\title{
Low Level Laser Therapy (LLLT) in the Effective Management of Recurrent Aphthous Ulcers (RAU): Clinical Case Reporting 3 Patients: A Case Series
}

QR CODE

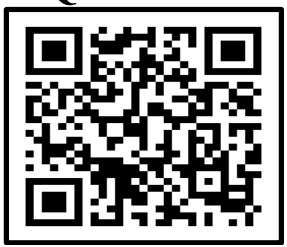

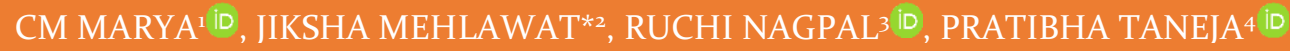

Low-Level Laser therapy (LLLT) was employed for the treatment of three patients diagnosed with recurrent aphthous ulcers (RAU's) The patients presented with recurrent aphthous ulcers in the region of floor of the mouth and buccal mucosa. The three patients with RAU's were provided with a wavelength of $946 \mathrm{~nm}$ starting the use at $320 \mu \mathrm{m}$ fibre optic at a distance of $1-3 \mathrm{~mm}$, peak power of $2 \mathrm{~W}$, frequency $10 \mathrm{~Hz}$ with no tissue contact in circular motion from outside to inside for 2 cycles with $100 \%$ duty for $30 \mathrm{~s}$ for 3 consecutive days. The LLLT made possible an effective improvement in the reduction of pain and size associated with ulcers. It proved to be a safe and cost effective therapy in the management of recurrent aphthous ulcers.

KEYWORDS: Recurrent Aphthous Ulcers, Low Level Laser Therapy, Apthae

\begin{abstract}
INTRODUCTION
In terms of population, India is the second largest country in the world with more than 1.3 billion populations. Despite being fastest growing economy, it stands way behind in terms of education, standard of living and health. ${ }^{\text {}}$ Oral health is a critical but overlooked component of overall health and well-being among adults. ${ }^{2}$ Despite being largely preventable, oral diseases are highly prevalent throughout the life course and have substantial negative effects on individals. $3,4,5$ In modern society, a number of diseases have been on the rise with changing lifestyles or environmental influences including diet and psychoemotional stress. Such impact may continue to the development and prevalence of various diseases including arteriosclerosis, cancer, chronic liver disease/ cirrhosis, chronic obstructive pulmonary disease (COPD), diabetes, hypertension, heart diseases, stroke, recurrent aphthous stomatitis, asthma, obesity, depression and vascular dementia. ${ }^{6,7}$
\end{abstract}

In an otherwise healthy individual, there are few conditions that develop in the oral mucosa. Aphthous ulcerations, commonly referred to as "canker sores," are the most prevalent oral mucosal lesions which affects the population more than $20 \%$. The term "aphthous" is derived from a Greek word "aphtha" which means ulceration. ${ }^{8}$ Recurrent aphthous stomatitis (RAS) has been described under three different clinical variants as classified by Stanley in
1972. Mikulicz's aphthae are the mild RAS or mild aphthous ulcers, major RAS also known as periadenitis mucosa necrotica recurrens or Sutton's disease, and Herpetiform ulceration characterized by recurrent crops of multiple ulcers which may be up to 100 in number. ${ }^{9}$

It is a distinct oral condition of unknown etiology characterized by the spontaneous emergence of more than 2 bouts of oral ulcers per year, not associated with an underlying systemic abnormality. ${ }^{10}$ The outbreak of RAS are associated with hereditary, psychological and socioeconomic stresses; nutritional deficiencies; hormonal fluctuations; and immunologic deficiencies. ${ }^{11-16}$ There is some evidence that suggests RAS ulcers are related to modified immunologic defenses or may be symptoms of several pathogens, rather than one. Due to the indeterminant aetiology of these lesions, it is often difficult to find a definitive cure. ${ }^{17,18,19}$

Several agents are helpful in the management of aphthous ulcers including antibiotics, antiinflammatory, immune modulators, anesthetics and alternative products.20 In most patients, topical agents including over the counter preparation such as antiseptic mouthwashes are recommended..$^{21}$ Topical agents enhances reparative and regenerative processes, contributes to activation of aerobic metabolic

(C) CM Marya et al. This is an open access article distributed under the terms of the Creative Commons Attribution License CC-BY-NC 4.0, which permits unrestricted use, distribution and reproduction in any medium, provided the use is not commercial and the original author(s) and source are cited. 
processes and oxidative phosphorylation, increases oxygen consumption in vitro and stimulate the transport of glucose into the cells.

Currently used topical antibacterial, antiinflammatory, immunomodulatory or symptomatic treatments for the condition are neither $100 \%$ reliable nor efficacious. There is currently no single wellestablished treatment for these common mouth ulcers, and none of the existing treatments accelerate the healing process. ${ }^{21-25}$

Recently, lasers have been used to treat various forms of oral lesions including RAS because of its biomodulation, analgesic effect by stimulation of healing process, promoting immediate relief of pain without an overdose of medication or side-effects and prevention of recurrence. ${ }^{8,26}$ Studies have suggested that low-level laser therapy (LLLT) has the potential to treat aphthous ulcer and related lesions. It is a safe and clinically effective therapy for treating RAS which also provides time benefit to the patients. ${ }^{8}$ This measure of treatment gives the dentist an interesting opportunity to expand the range of services offered in the practice and to alleviate the discomfort of patients quickly and easily.

The clinical case reports of the subjects reported with aphthous ulcer describes and analyzes the diagnosis and/or the management of one or two patients acts as the first line of evidence in health care. This case series is a powerful source to disseminate information on unusual clinical syndromes, disease associations, unusual side effects to therapy, or response to treatment. Case reports regarding aphthous ulcers and their treatment may be used as a means to teach health sciences students. Therefore, the aim of this paper is to critically appraise and epitomize clinical studies to ascertain whether laser therapy is an effective treatment option for treating aphthous ulcer through this case series.

\section{CASE REPORTS}

Three patients with the chief complaint of recurrent painful ulcers in the oral cavity came to the institutional department of Oral Medicine and Radiology. On clinical examination, oral ulcers of different dimensions were observed having erythematous halo on buccal mucosa, labial mucosa, tongue, floor of the mouth etc. The diagnosis of recurrent aphthous ulcers was made on the basis of detailed medical history and the clinical criteria given by Natah et al. in 2004. A meticulous history was taken to eliminate other ulcerative conditions such as Crohn's disease, celiac disease, neutropenia, HIV infection, and Behcet's syndrome. An informed consent was taken and an information sheet consisting of all the details of the procedure was provided to all the patients.

All the patients reported with the recurrent history of aphthous ulcers were provided with Low Level Laser Therapy (LLLT) for three consecutive days of wavelength 940nm diode laser, which was started using $320 \mu \mathrm{m}$ fiber optic at a distance of $1-3 \mathrm{~mm}$ from the lesion. It was provided with circular motion from the periphery of the ulcer to the center for 2 cycles with $100 \%$ duty for 30 seconds. The estimation of reduction in pain was done using VAS score o to 10 and in size of the ulcer using divider and ruler with an accuracy of 1 $\mathrm{mm}$. The recordings were made just before the treatment, the next day and third day of the laser therapy.

\section{CASE I}

A 78-year-old patient presented an 8 week history of episodes of recurrent aphthous ulcers on the labial mucosa [figure $1(a)$ ]. Patient had difficulty in speech and while eating. The size of the ulcer was $2.5 \mathrm{~mm}$ in length and $5.5 \mathrm{~mm}$ in width. The ulcer was not associated with any type of discharge and was tender on palpation. The patient used various chemotherapeutic aids such as topical anaesthetics for the management of aphthous ulcer, but the lesion recurred. He was provided with the laser therapy and lesion was observed for healing [figure 1(b)]. The readings of the reduction in ulcer pain and size are given in table 1.

\begin{tabular}{|c|c|c|c|}
\cline { 2 - 4 } & \multicolumn{3}{c|}{ SCORES } \\
\hline $\begin{array}{c}\text { Daye of the } \\
\text { ulcer (in mm) }\end{array}$ & $\begin{array}{c}2.5 \times 5.5 \\
\mathrm{~mm}\end{array}$ & $\begin{array}{c}2.5 \times 4.5 \\
\mathrm{~mm}\end{array}$ & $1.5 \times 4 \mathrm{~mm}$ \\
\hline $\begin{array}{c}\text { Pain perceived } \\
\text { (scale 0-10) }\end{array}$ & 10 & 7 & 0 \\
\hline
\end{tabular}

Table 1. Ulcer pain and size score at three-point times (Case I)

\section{CASE II}

A 23-year-old patient presented a 3 months history of recurrent aphthous ulcers on the floor of the mouth [figure 2(a)]. She had difficulty while chewing and 

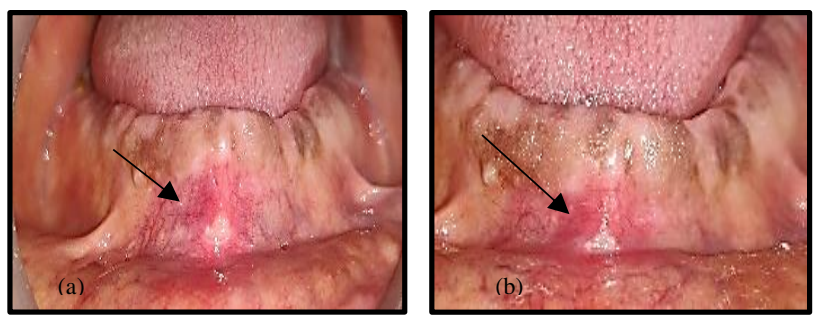

Figure 1. Case I (a) Pre-treatment and (b) Post-treatment

speaking. The size of the ulcer was $4 \mathrm{~mm}$ in length and $6 \mathrm{~mm}$ in width. The ulcer was very tender to palpate. She tried various home remedies for treating aphthous ulcers but it kept on recurring. She was provided with low level laser therapy. She reported that ulcer started to heal early than the previous times and also there was immediate reduction in pain after the first exposure to the laser therapy [figure $2(\mathrm{~b})]$. The readings of the reduction in ulcer pain and size are given in table 2.

\begin{tabular}{|c|c|c|c|}
\hline \multicolumn{1}{|c|}{ Day 1 } & Day 2 & Day 3 \\
\hline $\begin{array}{c}\text { Size of the } \\
\text { ulcer (in mm) }\end{array}$ & $4 \times 6 \mathrm{~mm}$ & $3 \times 5 \mathrm{~mm}$ & $\begin{array}{c}2.5 \times 4 \\
\mathrm{~mm}\end{array}$ \\
\hline $\begin{array}{c}\text { Pain } \\
\text { perceived } \\
\text { (scale } 0-10)\end{array}$ & 10 & 6 & 0 \\
\hline
\end{tabular}

Table 2. Ulcer pain and size score at three-point time (Case II)
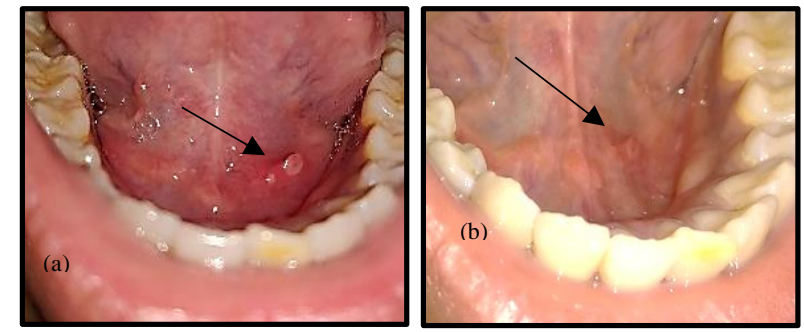

Figure 2. Case II (a) Pre-treatment and (b) Post-treatment

\section{CASE III}

A 42-year-old patient reported a history of 2 months recurrence of aphthous ulcers on the ventral surface of the tongue [figure $3(\mathrm{a})]$. He faced difficulty to speak, drink and while chewing. The size of the ulcer was 6 $\mathrm{mm}$ in length and $3 \mathrm{~mm}$ in width. The ulcer was round with erythematous halo. It was not associated with any type of discharge and was highly tender to palpate. The medical and family history were not of any contribution. The patient used pharmacological modes such as topical application of lignocaine and systemic vitamin B complex, which caused no improvement in discomfort and pain of the aphthous ulcer. He was given treatment using low level laser therapy to heal the lesion. He reported complete relief of pain and significant reduction in size of ulcer in 4 days and there was no discomfort. There were no side-effects reported of LLLT in the patient [figure $3(\mathrm{~b})$ ]. The readings of the reduction in ulcer pain and size are given in table 3.

\begin{tabular}{|c|c|c|c|}
\hline \multirow{2}{*}{} & \multicolumn{3}{c|}{ SCORES } \\
\hline $\begin{array}{c}\text { Size of the } \\
\text { ulcer (in mm) }\end{array}$ & $6 \times 3 \mathrm{~mm}$ & $\begin{array}{c}\text { Day 2 } \\
4 \times 2.5 \\
\mathrm{~mm}\end{array}$ & $3 \times 1.5 \mathrm{~mm}$ \\
\hline $\begin{array}{c}\text { Pain } \\
\text { perceived } \\
\text { (Scale 0-10) }\end{array}$ & 10 & 3 & 0 \\
\hline
\end{tabular}

Table 3. Ulcer pain and size score at three-point times (Case III)
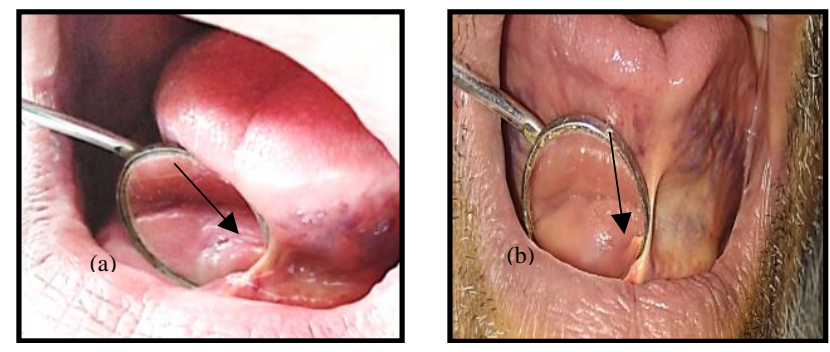

Figure 3. Case III (a) Pre-treatment and (b) Post-treatment

\section{DISCUSSION}

The aphthous ulcers may occur in the oral cavity due to differential reasons. While evaluating the patients with oral symptoms, Infection-causing ulceration in the mouth should also be considered. A common infection, particularly in patients with HIV infection and aphthae is herpes. Other viral, bacterial, treponemal and fungal agents have the potential to cause mouth ulcers. Several autoimmune diseases may mimic benign aphthous ulcers. Behçet's syndrome is an autoimmune vasculitis that causes recurrent oral and genital ulcerations, uveitis and retinitis. Lupus erythematosus, bullous pemphigoid and pemphigus vulgaris are other diseases that may involve ulceration of the mouth. In all of these conditions, the associated symptoms should be elicited to make a differentiation from benign recurrent aphthae. ${ }^{27}$

Numerous agents aids in the management of aphthous ulcers including antibiotics, anti-inflammatory, 
immune modulators, anaesthetics and alternative products. ${ }^{6}$ Topical agents enhances reparative and regenerative processes, provides to activation of aerobic metabolic processes and oxidative phosphorylation, increases oxygen consumption and stimulate the transport of glucose into the cells.7 Pertaining to pain relief, one mechanism that has been proposed is modulation of pain perception by modification of nerve conduction via the release of endorphins and enkephalins. ${ }^{8}$ The main purpose of treatment is to decrease pain and size of the ulcer. ${ }^{9}$ The results of the study conducted showed that Low Level Laser Therapy has the magnitude of reducing the pain intensity and size of aphthous ulcers. Healing is the main characteristic of LLLT including three main factors. First, there is an increment of adenosine triphosphate (ATP) production, as laser is considered to raise the production of ATP, leading to a boost in mitotic activity and to an increase in protein synthesis by mitochondria, resulting in greater tissue regeneration in the repair process. Second, there is a stimulus to microcirculation, which increases the delivery of nutritional elements associated with increased speed of mitosis, facilitating cell multiplication. Finally, new vessels are formed from pre existing vessels. ${ }^{9} \mathrm{~A}$ study conducted by De Souza et al. in 2010 revealed that $75 \%$ of the patients reported a reduction in pain in the same session after laser treatment and total regression of the lesion occurred after 4 days. ${ }^{28}$ Khademi et al. found similar benefits of quicker healing and reduced pain after using low levels of laser treatment on RAS. ${ }^{29}$ Similarly the LLLT study was effective in relieving pain and reducing the healing time during the treatment of aphthous ulcers conducted by Aggarwal et al. ${ }^{\circ}$

Hence it summarizes, as there are no medications, the side effects and risk of overdosage could also be prevented. Hence, it can be concluded that LLLT is a safe and clinically effective therapy for treating RAUs, which also provides time benefit to the patients. The outcomes from the present study which standout are, the immediate and lasting pain relief, and the accelerated ulcer healing. Limitation of the study includes subjective evaluation of pain perception. Though healing occurs through medications and laser therapy but mainly depends on host immune response and microbe interaction.

\section{CONCLUSION}

LLLT employed as a treatment measure for the management of recurrent aphthous ulcers in the current case report not only provided instant pain relief but a rapid decrease in the size of the lesion was also seen. It is safe, clinically effective therapy for treating RAU, which also provides time benefit to the patients.

\section{REFERENCES}

1. Census (2011), Primary Census Abstracts, Registrar General of India, Ministry of Home affairs, Government of India. (Online Article) Available from http://www.census2o11.co.in/facts/topdistrictpopulatio n.html. [Last accessed on $10^{\text {th }}$ July, 2020].

2. Raju SH, Fareed N, Sudhir KM, Krishna Kumar R. Caries risk assessment among subjects with periodontal disease using cariogram study model. J Indian Assoc Public Health Dent. 2016;14:266-71. https://doi.org/10.4103/2319-5932.189838

3. Kassebaum NJ, Smith AGC, Bernabé E, et al. Global, regional, and national prevalence, incidence, and disability-adjusted life years for oral conditions for 195 countries, 1990-2015: a systematic analysis for the global burden of diseases, injuries, and risk factors. J Dent Res. 2017; 96: 380-7. https://doi.org/10.1177/oo22034517693566

4. Petersen PE, Bourgeois D, Ogawa H, Estupinan-Day $\mathrm{S}$, Ndiaye $\mathrm{C}$. The global burden of oral diseases and risks to oral health. Bull World Health Organ. 2005; 83: 661-9.

5. Peres MA, Macpherson LMD, Weyant RJ, Daly B, Venturelli R, Mathur MR, Listl S, Celeste RK, Herreño CCG, Kearns C, Benzian H, Allison P, Watt RG. Oral diseases: a global public health challenge. The Lancet 2019; 394: 249-6o. https://doi.org/10.1016/So1406736(19)31146-8

6. Al-Omiri MK, Karasneh J, Lynch E. Psychological profiles in patients with recurrent aphthous ulcers. Int J Oral Maxillofac Surg.2012;41(3):384-8. https://doi.org/10.1016/j.ijom.2011.12.024

7. Gurleyen EK, Erişen MO, Cakir O, Uysal O, Gulsum AK. Quality of life in patients with recurrent aphthous stomatitis treated with a mucoadhesive patch containing citrus essential oils. Patient Preference and Adherence 2016:10 967-73. https://doi.org/10.2147/PPA.S106530

8. Anand V, Gulati M, Govila V, Anand B. Low level laser therapy in the treatment of aphthous ulcer. Indian Journal of Dental Research.2013;24:267-70.

9. Stanley HR. Aphthous lesions. Oral Surg Oral Med Oral Pathol 1972;30:407-16.

10. Tappuni AR, Kovacevic T, Shirlaw PJ, Challacomb SJ. Clinical assessment of disease severity in recurrent aphthous stomatitis. J Oral Pathol Med. 2013;42:635-41. 
11. Pederson A, Klausen B, Hougen HP, Stenvang JP. Tlymphocyte subsets in recurrent aphthous ulceration. J Oral Pathol Med 1989;18:59. 10.1111/jop.12059

12. Nsamba C, Kaluskar SK. Inheritance of recurrent aphthous ulceration of the mouth. J Laryngol Otol 1986;100:361.

13. Ship II, Morris AL, Durocher RT, Burket LW. Recurrent aphthous ulcerations in a professional school student population. IV. Twelve month study of natural disease patterns. Oral Surg Oral Med Oral Pathol. 1961;4:30.

14. Crivelli MR, Adler SAI, Quarracino C, Bazerque P. Influence of socioeconomic status on oral mucosa lesion prevalence in school children. Community Dent Oral Epidemiol. 1988;16:58.

15. Wray D, Ferguson MM, Mason DK, Hutcheon AW, Dagg JH. Recurrent aphthea: Treatment with vitamin $\mathrm{B}^{\wedge}$. folic acid and iron. Br Med J. 1975; 212:490.

16. Ferguson MM, Carter J, Boyle P. An epidemiological study of factors associated with recurrent aphthae in women. J Oral Med. 1984;39:212.

17. Scully C, Porter S. Recurrent aphthous stomatitis: current concepts of etiology, pathogenesis and management. J Oral Pathol Med. 1989; 18(1):21-7.

18. Vivek V, Nair BJ. Recurrent Aphthous Stomatitis: Current Concepts in Diagnosis and Management. JIAOMR 2011;23(3):232-6. https://doi.org/ 10.5005/jpjournals-10011-1135

19. American Academy of Periodontology. Proceedings of the World Workshop in Clinical Periodontics. Chicago: American Academy of Periodontology 1989; $\mathrm{X}-9$.

20. Mcbride DR. Management of Aphthous Ulcers. Am Fam Physician.200o;62(1):149-54.

21. Hamdy AAEM, Ibrahem MAE. Management of Aphthous Ulceration with Topical Quercetin: A Randomized Clinical Trial. J Contemp Dent Pract. [Internet]. 2010; 11(4):9-16.
22. Woo SB, Sonis ST. Recurrent aphthous ulcers: a review of diagnosis and treatment. J Am Dent Assoc. 1996; 127(8):1202-13.

23. Bagán JV, Sanchis JM, Milián MA, Peñarrocha M, Silvestre FJ. Recurrent aphthous stomatitis. A study of the clinical characteristics of lesions in 93 cases. J Oral Pathol Med. 1991; 20(8):395-7.

24. Ueta E, Osaki T, Yoneda K, Yamamoto T, Kato I. A clinical trial of Azelastine in recurrent aphthous ulceration, with an analysis of its actions on leukocytes. J Oral Pathol Med. 1994; 23(3):123-9.

25. Calvo TR, Lima ZP, Silva JS, Ballesteros KV, Pellizzon CH, Hiruma-Lima CA, Tamashiro J, Brito AR, Takahira RK, Vilegas W. Constituents and antiulcer effect of Alchornea glandulosa: activation of cell proliferation in gastric mucosa during the healing process. Biol Pharm Bull. 2007; 30(3):451-9.

26. Bladowski M, Choroszucha HK, Choroszucha T. Comparison of treatment results of recurrent aphthous Stomatitis (RAS) with low and high power laser irradiation vs a pharmaceutical method ( 5 year study).

J Oral Laser Applications. 2004;4:191-209.

27. David R. Mcbride. Management of aphthous ulcers. Am Fam Physician. 2000;62(1):149-54.

28. De Souza TO, Martins MA, Bussadori SK, Fernandes KP, Tanji EY, Mesquita Ferrari RA, et al. Clinical evaluation of low level laser Low level laser treatment for recurring aphthous stomatitis. Photomed Laser Surg. 2010;28:S85-8.

29. Khademi H, Shirani AM, Nikegbal F. Evaluation of low level laser therapy in recurrent aphthous stomatitis. J Dent Shiraz Univ Med Sci. 2009;10:16o 2. 30. Aggarwal H, Singh MP, Nahar P, Mathur H, Sowmya GV. Efficacy of Low Level Laser Therapy in Treatment of Recurrent Aphthous Ulcers. Journal of Clinical and Diagnostic Research 2014,8(2):218-20. https://doi.org/10.7860/JCDR/2014/7639.4064.

\section{AUTHOR AFFILIATIONS: ${ }^{*}$ Corresponding Author)}

1. Professor and Head (https://orcid.org/oooo-0003-3117-0312)

2. Post Graduate Student

3. Professor (https://orcid.org/oooo-0oo3-0442-7418)

4. Assistant Professor (https://orcid.org/oooo-0002-9805-2436)

Dept. of Public Health Dentistry, Sudha Rustagi College of Dental Sciences and Research, Faridabad, Haryana 